\title{
Implications of Carbon Cap-and-Trade for Electricity Rate Design, with Examples from Florida
}

By Hethie Parmesano and Theodore J. Kury*

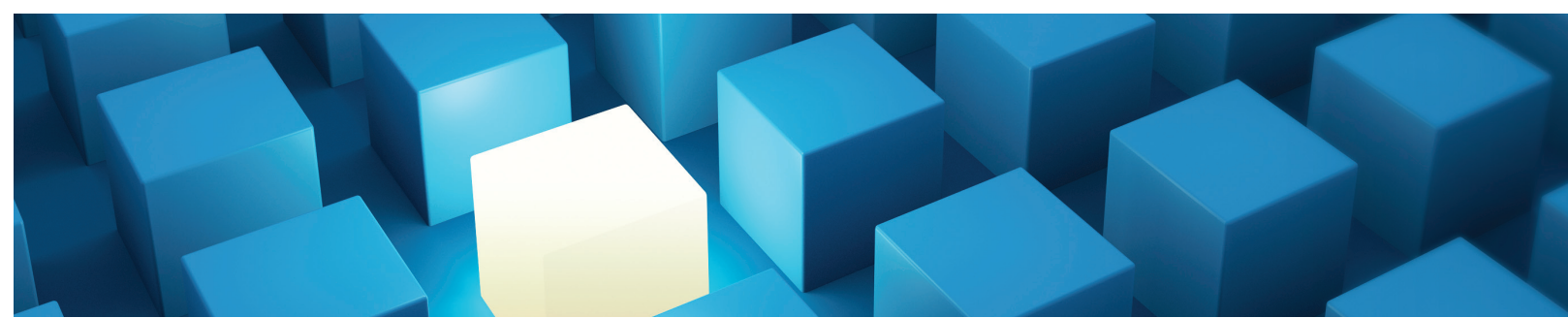

\begin{abstract}
The price of emissions allowances will affect the structure of the utility's costs, which has implications for rate design and load management programs. Under a cap-and-trade program to control carbon dioxide emissions, electric utilities (and other electricity generators and emitters of carbon covered by the legislation) would have to obtain permits (allowances) for the carbon emitted in the process of producing goods and services. Depending on the design of the program, how allowances are allocated or auctioned, what happens to the auction revenue, the total allowances available each year, and what actions are taken to reduce emissions, utility total revenue requirements will be affected. This paper addresses these implications and provides insight into how utilities' marginal costs of energy might change and the potential effects on policies whose goal is to influence consumer behavior. Those insights are illustrated with specific examples from an electric generation dispatch model developed for the state of Florida. We find that a cap-and-trade program can have a marked effect on the characteristics of the marginal costs of electricity production. The cost difference between peak and the off-peak hours can change not only through time, but also with changes in the assumed the price of $\mathrm{CO}_{2}$ allowances. These changes can also, under certain conditions, reduce the economic value of technologies designed to shift the consumption of electricity from one time period to another. The paper emphasizes the importance of detailed study in evaluating possible unintended consequences of energy policy.
\end{abstract}




\section{Introduction}

The production of carbon dioxide is a by-product of many production processes, including the generation of electricity through the combustion of fossil fuels. However, some people argue that there are additional costs - called 'externalities' by economists-associated with the combustion of fossil fuels that are not reflected in the current prices for those fuels, and that the production of carbon dioxide is causing changes in the planet's climate that will one day prove harmful to the inhabitants. They further argue that the costs associated with adapting to these changes should be borne by the consumers of today. The skeptics argue either that additional carbon dioxide is not contributing to change in the planet's climate or that the consumers of today should not be responsible for the costs associated with it. As most governments in the world today have not adopted a price for $\mathrm{CO}_{2}$ emissions, it is likely that either the latter view is more widely reflected in the policies of the world's governments, or that the governments are uncertain over the proper mechanism to recover such costs. However, there is a growing trend toward the view that carbon externalities should be included in electricity prices, as many governments are contemplating such a pricing mechanism.

Under a cap-and-trade program to control carbon dioxide emissions, electric utilities (and other electricity generators and emitters of carbon) will have to obtain permits (allowances) for the carbon emitted in the process of producing goods and services. The goal of a cap-and-trade program is to reduce carbon emissions by covered activities to specific levels (the total amount of allowances) through a market mechanism that puts a price on carbon emissions. ${ }^{1}$ The idea is that producers of goods and services that generate carbon emissions, as well as users of those goods and services, will then make production and consumption decisions that take carbon costs into account. Thus, instead of a command and control approach to reducing emissions, the program provides incentives for those with a low cost of reducing emissions to do so, allowing high compliance cost emitters to purchase their allowances. If all goes according to plan, the target level of emissions will be achieved at the lowest possible cost for producers and consumers.

Depending on the design of the program, how allowances are allocated or auctioned, what happens to the auction revenue, the total allowances available each year, and what actions are taken to reduce emissions, utility total revenue requirements will be affected. But the price of allowances will also affect the structure of the utility's costs, which has implications for rate design and load management programs. This paper addresses those implications and provides insight into how utilities' marginal costs of energy might change and the potential effects on policies whose goal is to influence consumer behavior. Those insights are illustrated with specific examples from a model developed for the state of Florida. 


\section{The Big Picture-What Does a Carbon Cap-and-Trade Program Mean for Utilities?}

The utility (and non-utility generators) will obtain allowances sufficient to cover their emissions. They may be given some for free and purchase others through centralized auction and secondary markets. If the utility ends up with more allowances than it needs, it will sell the excess in the secondary market or save the allowances for the future if that is permitted by program rules. Some revenues from the central auctions may be given to utilities to reduce the impact of the program on their total revenue requirement and retail rates. ${ }^{2}$ Meanwhile, the utility will be looking for cost-effective measures it can take to reduce its need for allowances, which will either reduce the number that it must purchase or free up more allowances for sale to other emitters.

The cost-effectiveness of these measures will depend on the cost of allowances, which in turn will depend on the supply and demand for carbon-reducing measures nationwide (or worldwide), and on the carbon-reducing options available to the particular utility. For example, if the market price of an allowance is expected to be $\$ 60 /$ ton, the utility will take actions that reduce its emissions if the cost of achieving the reductions can be accomplished for less than $\$ 60$. If the available carbon-reducing measures cost more, the utility will purchase the additional allowances needed. Of course the actual cost-benefit calculation is much more complicated, since many of the carbon-reducing mechanisms are long-lived and will, therefore, affect the allowances needed over many years. Each utility will need to develop a strategy for dealing with cap and trade, and update that strategy as more information about likely allowance prices and emission-reducing technologies emerges.

What might some of the options available to electric utilities be? There are several categories:

1. Reduce demand through innovative pricing mechanisms that set the price for marginal consumption at the marginal cost of supplying the power including carbon costs.

2. If efficient pricing is not achievable or there are market imperfections that interfere with consumers' ability to respond to those prices, implement other types of load management programs, and possibly subsidize customer switching to more efficient equipment or alternative energy sources (e.g., roof-top solar).

3. Switch to lower emission sources of electricity-essentially changing the resource mix from generation technologies with high emissions to technologies with low or no emissions.

4. Invest in offsets - If the program permits, utilities may be able to plant trees, protect rainforests, or take other measures that will offset their emissions and reduce the number of allowances they need. 


\section{Changing Utility Costs and Cost Structures}

Introduction of a cap-and-trade program will affect electric utility costs in three ways. First, the total cost, and therefore the total revenue requirement, will likely be affected. Many of the versions being discussed in Congress would offset some of the cost of greenhouse gas emissions allowances that, for example, coal-intensive utilities will require, by giving some allowances for free or rebating some of the revenues from allowance auctions based on the utility's emission in some past period. However, these provisions will probably not keep every utility's revenue requirement unchanged, and most proposals would phase out free allowances and rebates over a period of years. Furthermore, going forward, utilities that find inexpensive ways to reduce their carbon emissions will (depending on regulatory treatment) benefit from sales of excess allowances (and lower revenue requirements), and utilities that are unable to do so will have revenue requirements that rise more rapidly than without a cap-and-trade program.

The second way that utility costs will be affected is at the margin. Today when US utilities face an increase or decrease in demand by customers in a particular hour, the marginal cost of the energy involved is typically either the wholesale market price of energy for delivery in that hour or, in the case where the utility is not participating in the wholesale market, the incremental fuel and variable O\&M expense ${ }^{3}$ of the utility's unit that is operating at the margin in that hour. ${ }^{4}$ Once the cap-and-trade program is in place, the marginal cost of energy will include the cost of any associated emission allowances. If a utility is not participating in the wholesale market, its marginal energy cost will include the market value of any emissions allowances that must be used to cover output from the utility's marginal generator. In the more likely situation, in which the utility is a market participant, the marginal cost of energy is the market price, which will also include the market value of emissions allowances associated with the production of marginal energy in the regional market.

But this is only part of the story. As relative energy production costs (including allowances) of various types of generation change and as utilities (and regional energy markets) reconfigure their generation resource mix in response to the cap-and-trade program, the resource "stack" that defines which units are operating in which hours (whether the focus is on an individual utility or the entire region) may change. Depending on the price of emissions allowances, the unit operating on the margin will likely be different from a base case without cap-and-trade, at least in some hours.

New generation and storage technologies adopted as a result of the cost of emissions allowances may also affect the marginal cost of capacity. In addition, the cap and trade program may provide free allowances to certain technologies in a way that is correlated with installed capacity, which may also affect the marginal cost of capacity. ${ }^{5}$

As the resource mix and dispatch order changes, the pattern of utility energy costs across the hours of the year will also be affected. This is the third effect of a cap-and-trade program on utility costs. These changes in the time pattern of energy costs are important because the time pattern is a key driver for time-of-use electric rates and affects the optimal design and costeffectiveness of programs designed to shift loads from high-cost to low-cost periods. 
The effects of these emissions allowances on the electric generators in a region depend on many factors, such as the types of generation deployed, the types of fuel that is used, and the number and size of the generating units. Because of the heterogeneity of these factors from geographic region to region, their analysis requires a model that can capture these factors. We have developed a chronological model of generation dispatch to study these effects. The dispatch model uses data available from the FERC and the EIA for individual generating units in the state of Florida, fuel forecasts from the 2010 Annual Energy Outlook, and load forecasts from the 2009 Florida Regional Coordinating Council Load and Resource Plan to study the effects of emissions prices on the market for electric generation in the state of Florida. The model, which adjusts the resource plan and the dispatch order as the emissions cost assumptions changes, is explained in more depth in Kury and Harrington (2010).

This model can be used to quantify the changes in the production of electrical energy that occur under various carbon prices and allow us to isolate the marginal effects of those changes in emissions price. However, the model results themselves are highly dependent on assumptions such as fuel prices, capital expenditures required to build additional generation, and the existing generation mix of the system under study. These model results, as they apply to the state of Florida, are interesting in the sense that they illustrate relationships that may be present within a particular region. It is very important that, before results are applied to different jurisdictions, comprehensive modeling of those jurisdictions is performed, and that assumptions used in modeling of any region are up-to-date and valid.

Charts 1 and 2 below show the marginal energy cost duration curves (which summarize the number of hours of the year with marginal energy costs at a particular level) for 2011 and 2017 under three assumed carbon prices $-\$ 0, \$ 60$ and $\$ 100$ per ton. Note that increases in emissions prices tend to flatten out the marginal cost duration curve. The $\$ 60 /$ ton emissions price eliminates the lower priced hours that exist in the case with no emissions price, while the $\$ 100$ emissions price eliminates the intermediate drop after about $25 \%$ of the hours in 2011 and 2017.

Chart 1. Marginal Cost Duration Curves for 2011 under various emissions prices

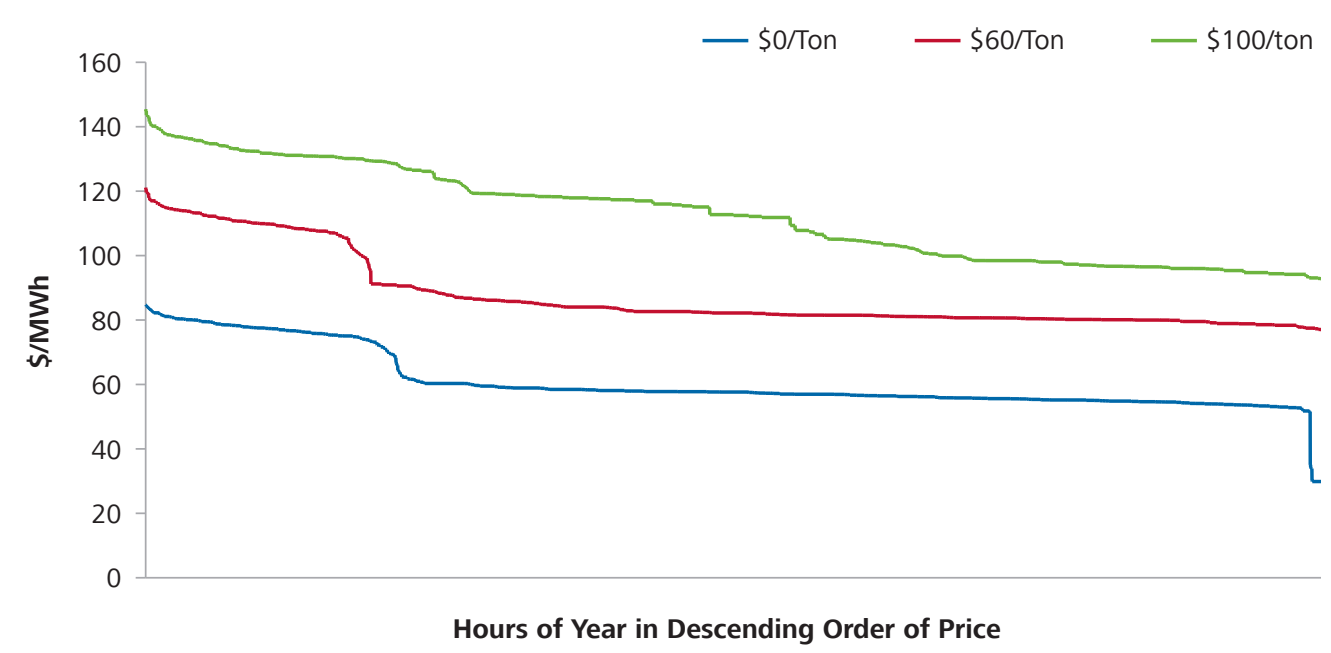


Chart 2. Marginal Cost Duration Curves for 2017 under various emissions prices

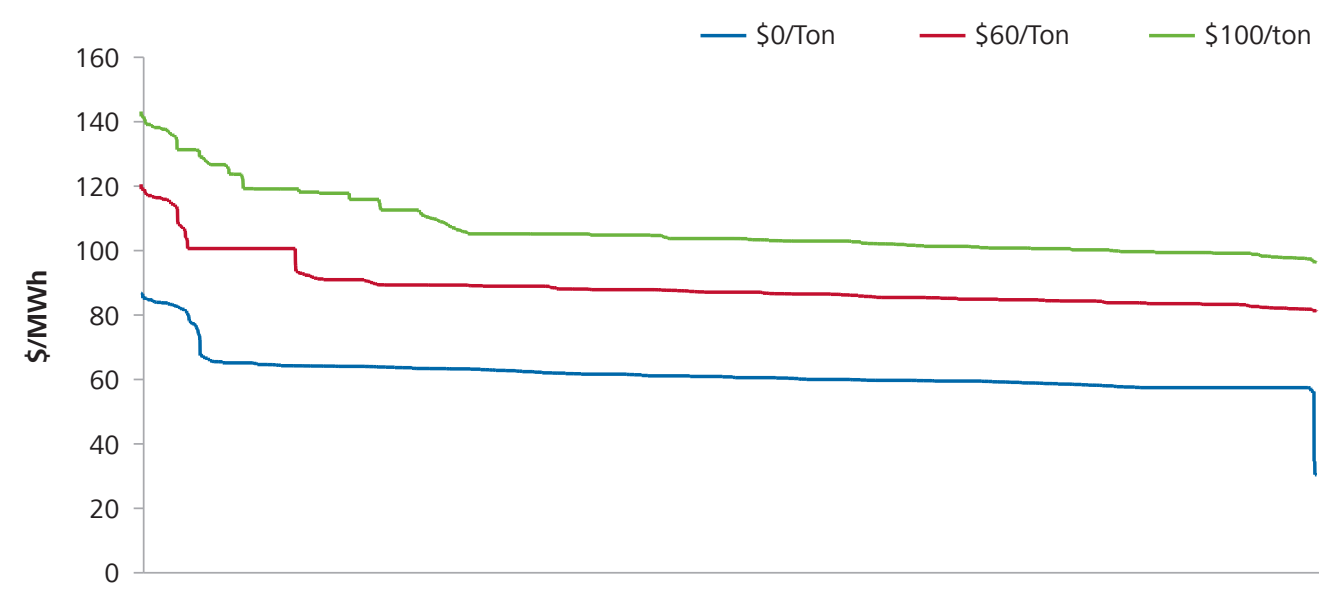

Hours of Year in Descending Order of Price

Charts 3 and 4 shed light on the reason for the changes in the marginal cost duration curves by illustrating the changes in generation mix that occur as emissions prices increase. Note that in 2011, there is still substantial coal-fired generation, even at high carbon prices, because there is not time to install new generation. However, by 2017 new nuclear power plants begin operation and a greater reduction in coal-fired generation is realized.

\section{Chart 3. 2011 MWh Production by Fuel Type}

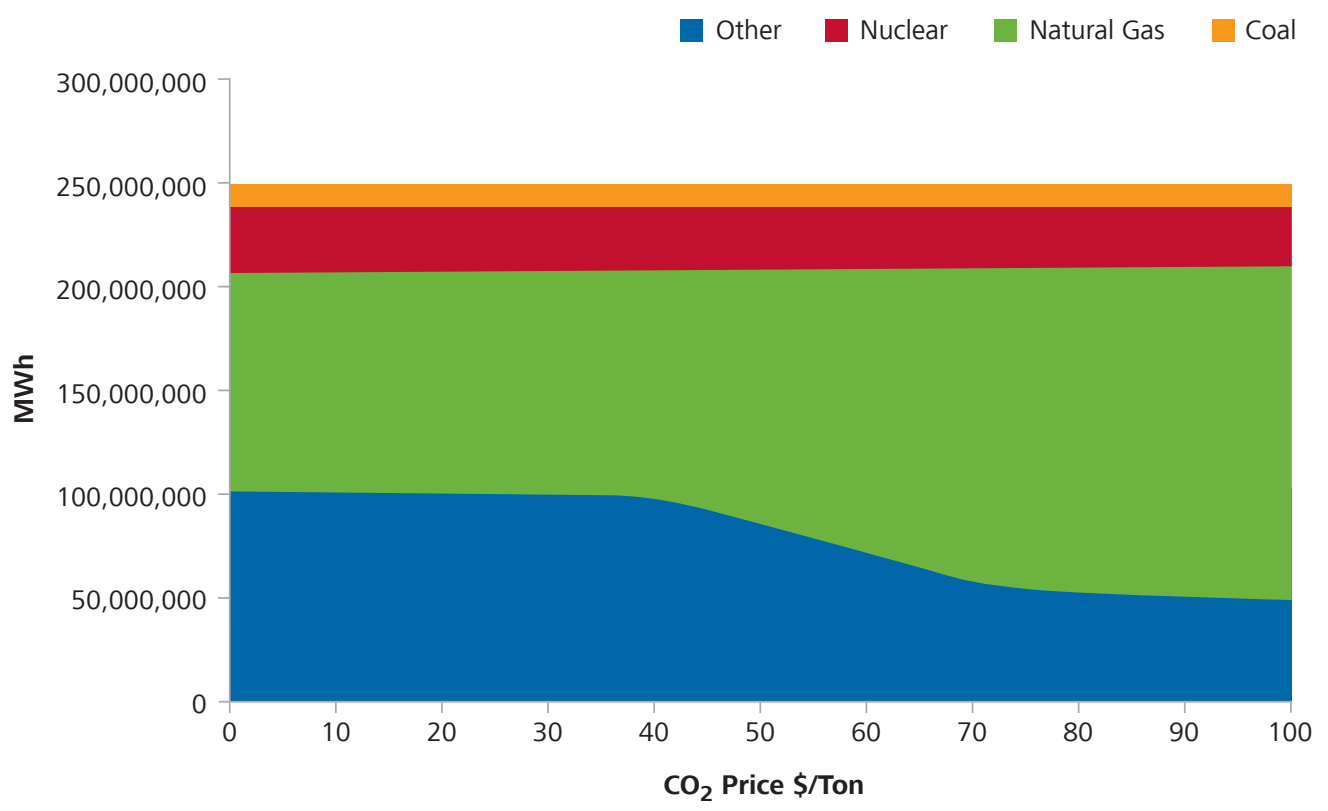




\section{Chart 4. 2017 MWh Production by Fuel Type}

Other

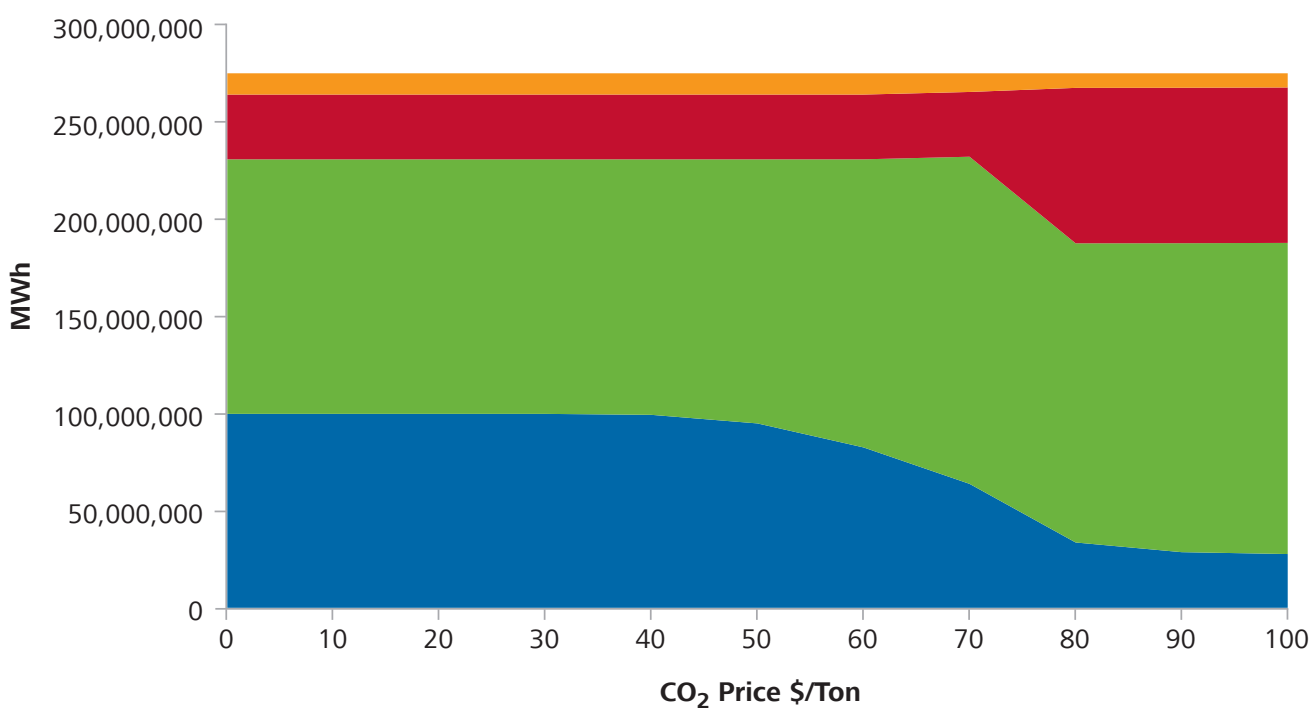

\section{Implications for Electric Rates and Other Demand Management Programs}

The goal of a cap and trade program for carbon is to achieve targeted reductions in carbon emissions at the lowest possible cost, through price signals to which producers and consumers respond. Economists have long urged the use of marginal costs in setting utility rates, so that consumers will make consumption decisions at the margin that reflect the additional costs incurred (or saved) as a result. Marginal costs are the basis for dynamic pricing programs such as real-time pricing, critical-peak pricing and critical peak rebates. Marginal cost differentials are typically the basis for time-of-use pricing. Some jurisdictions also use marginal costs as the basis for rate design more generally, and for class revenue allocation.

Rate experts have often argued among themselves over whether those marginal costs should include "external" social costs that are not directly incurred by the utility in providing the service, but are incurred by society more generally. ${ }^{6}$ The classic example of an externality is unregulated air pollution. Once the cap and trade program goes into effect, the cost of carbon emissions will no longer be external to the utility's operations, but will be internalized. If efficient pricing is the goal, then it is clear that carbon-related costs should be included in the marginal costs used as the basis for rates. Furthermore, if the goals of the cap and trade program are to be achieved at least cost, then customers should face prices for marginal use (what they pay for using more or save for using less) that reflect marginal costs including emissions allowance costs. 
We expect to see several types of changes in electric rates. First, upward pressure on total revenue requirements from allowance costs admeasures taken to reduce expenditures on carbon allowances will increase the focus on rates designed to encourage conservation and allow demand management, thereby reducing loads and revenue requirements. Investment in smart technology (including smart meters, smart grid components, and smart appliances) will make it easier to implement innovative rates and programs, and easier for consumers to respond to the new efficient price signals.

Second, the market price of energy, which will now include the cost of carbon emissions allowances, may be more volatile and hard to predict at the time of a rate case. Utilities may apply for automatic adjustments to rates to track changes in emissions allowance costs (and perhaps revenues from allowance trading), or market prices more generally. They may also want the ability to pass through certain costs of measures to reduce $\mathrm{CO}_{2}$ emissions without waiting for a full rate case.

Third, the pattern of costs (the third type of cost change discussed above) may mean that rate structures need adjustment:

- Period definitions in time-of-use rates may need adjustment, for example the peak period may need to be longer or a shoulder period introduced.

- Higher energy prices at the margin may be necessary to send efficient price signals. To be consistent with the overall revenue requirement, this may require inclining block rate structures or some form of customer baseline structure, under which a lower price would apply to a fixed amount of energy set in a previous period, with charges or credits at marginal cost for deviations from the baseline amount.?

- The relative size of energy and demand charges may need to change, at least in jurisdictions where rate design is based on marginal costs, as marginal energy costs rise relative to marginal capacity costs.

- Rates (and other DSM programs) designed to encourage shifting of load from peak to off-peak in an era with large differentials between peak and off-peak marginal costs may no longer be as appropriate as those designed to reduce consumption outright.

There are many energy efficiency policies designed to shift demand for electricity from peak to off-peak periods. Examples of these policies include the promotion of appliances that can be programmed to delay the start of their operating cycle, such as dishwashers and clothes dryers, and the promotion of plug-in hybrid electric automobiles that can consume stored electricity during the day and recharge their batteries during the night, and other short term storage devices for electricity, such as advanced battery technologies. The appropriateness and effectiveness of these policies depends critically upon the difference in peak and off-peak electricity prices. For example, if the consumer can avoid the consumption of electricity priced at $\$ 0.10$ per $\mathrm{kWh}$ and instead consume electricity priced at $\$ 0.06$ per $\mathrm{kWh}$, then the consumer will do so if the $\$ 0.04$ per kWh saving is sufficient to offset the consumer's cost of making the capital investments or lifestyle changes necessary to make the shift. If these prices reflect marginal costs, then a policy that encourages such a shift can be economically efficient. ${ }^{8}$ 
In establishing rate policies in a world with a carbon pricing mechanism, it is important to understand the pattern, volatility and uncertainty of carbon allowance prices and costs of dealing with the mechanism. It is also critical to understand the nature of the effects of emissions pricing on the differential between peak and off-peak prices, and whether this relationship changes through time. The decision whether to invest in energy efficiency technologies has long term implications for both consumers and utilities. A consumer who makes a decision to invest in technologies that allow her to shift load from the peak to the off-peak hours based on the current difference between on and off-peak prices is $\$ 0.04$ / kWh may find that the rate of return on the investment decision is inadequate if the spread shrinks over time. This could mean that the consumer's investment was not only a bad personal decision, but might also be an economically inefficient use of society's resources. Such experiences can discourage future efficient investment by consumers in these technologies.

We used the model described above to study the effect of emissions pricing on the differentials between peak and off-peak prices. Note that our calculations deal only with the energy portion of such prices. If marginal capacity costs are unchanged with respect to changes in emissions prices, then our calculations are representative of changes in efficient peak/off-peak rate differentials.

To derive the Chart 5 and 6 , we assumed that consumers have technology that allows them to shift usage from the $10 \%$ highest priced hours in the month to the $10 \%$ lowest priced hours. We have calculated the average of the $74^{9}$ highest priced hours in the month and the average of the 74 lowest priced hours in the month and computed their differential. This can be seen as the per-kWh economic benefit to the customer for shifting this load. Note that this technology, while illustrative, is not likely to exist, so these benefits should be seen as the best possible outcome assuming perfect foresight, but we can still learn from their relative shapes. Further, we have chosen $10 \%$ of the highest and lowest priced hours for this example, but the results are similar if we choose $5 \%$ or $20 \%$ of the hours. Chart 5 shows this differential for every July from the years 2011 through 2022.

\section{Chart 5. July Average Price Differential between 74 Peak and 74 Off-Peak Hours with Changes in Emissions Prices}

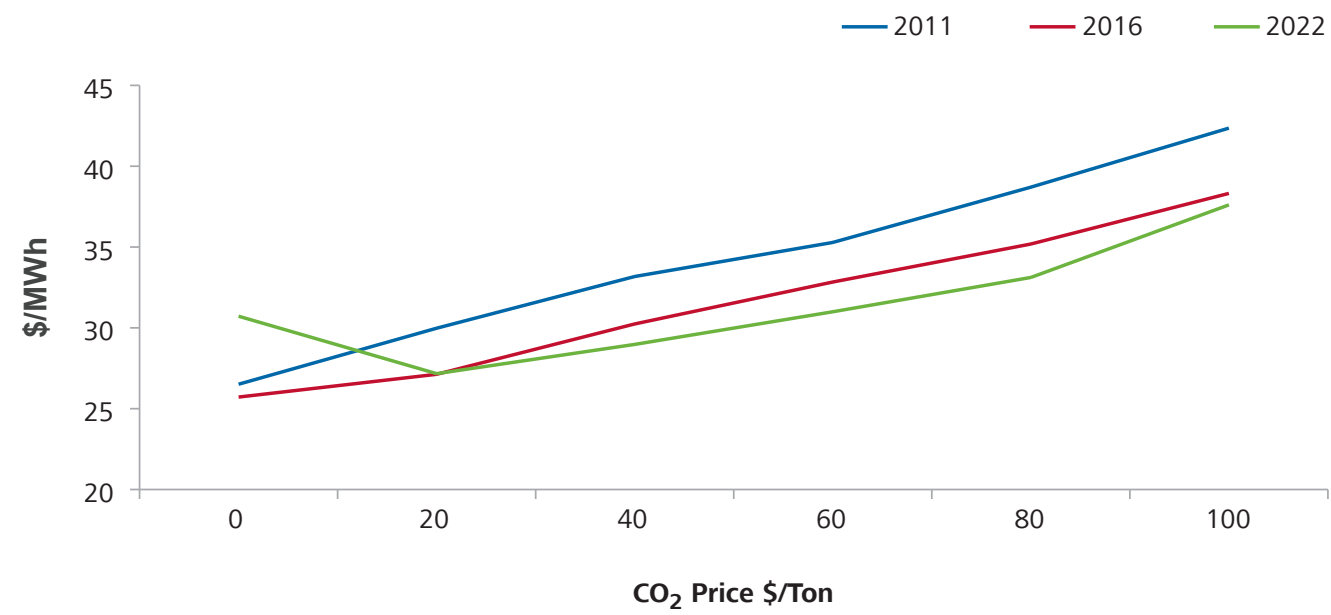


It is interesting to note that the differential increases as emissions prices increase. Therefore, as the price of $\mathrm{CO}_{2}$ increases, the economic benefit to the consumer from shifting load in this manner increases as well. However, as the supply market for generation matures and adjusts to the emissions prices, the differential decreases. In 2011, with a \$100/ton emissions price, this differential is approximately $\$ 43 / \mathrm{MWh}$, or $\$ 0.043 / \mathrm{kWh}$. At this price the differential falls to around \$38/MWh in 2016 and to approximately \$37/MWh by 2022. With no emissions price, however, this differential is approximately $\$ 26 / \mathrm{MWh}$ in 2011 and grows to $\$ 31 / \mathrm{MWh}$ in 2022. Therefore, the value of the consumer's investment is changing over time, but also varies depending on the prevailing emissions price.

Chart 6 shows this differential for the month of January.

\section{Chart 6. January Average Price Differential between 74 Peak and 74 Off Peak Hours with Changes in Emissions Prices}

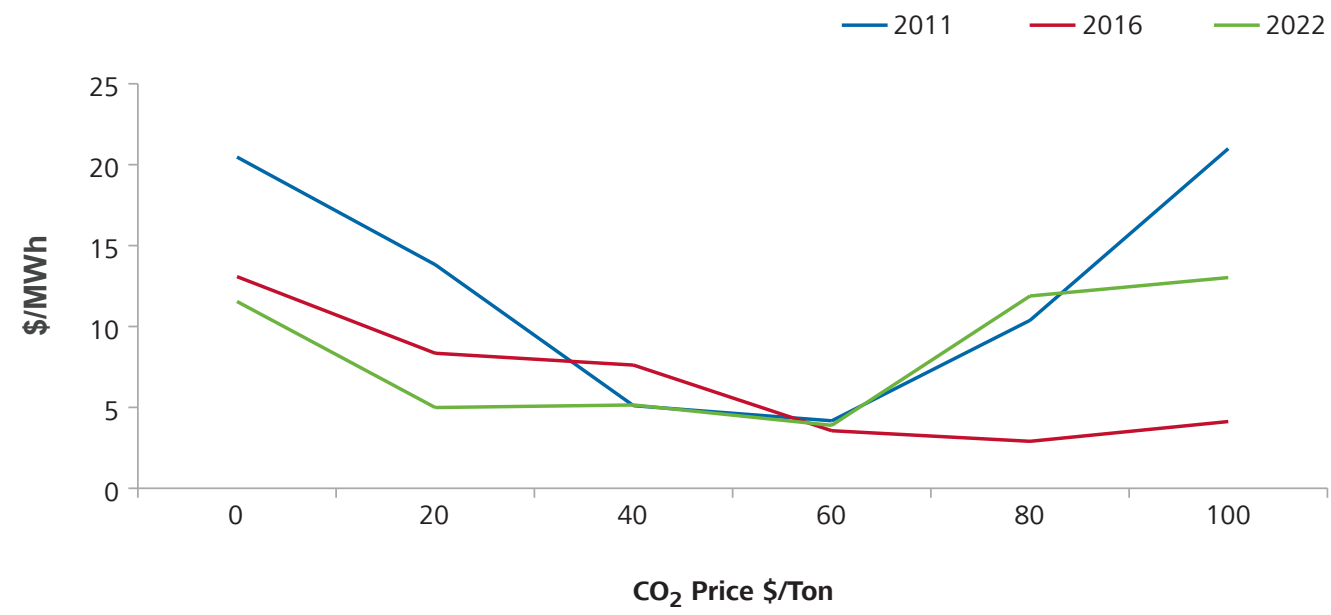

Chart 6 shows how dynamic the relationship between peak and off peak prices can be. Unlike the graph for July, emissions prices initially decrease the differential between peak and off peak prices. This means that any investment in technology that could shift load will decrease in value if the price of emissions is up to $\$ 80 /$ ton. In certain years this effect is drastic, from a $\$ 13$ differential under no emissions price in 2016 to a $\$ 3$ differential with an $\$ 80$ emissions price. That is, in 2016 an investment in this technology would lose $75 \%$ of its value during the month of January. It is also clearer how this relationship can change over time. The almost complete elimination of this differential in January is due to the current plan to construct four new nuclear generating units in the state of Florida in the latter part of the decade. 
A fourth rate implication of carbon cap and trade is the policy issues created by potential rebates of auction revenues. The purpose of rebating some auction revenues is to control the impacts on consumers' bills during a transition phase. A careful balance will need to be struck between this goal and the goal of sending efficient price signals. Policy makers will need to determine which customers should receive assistance and how it should be incorporated in the rates for those customers. Should the rebate revenues flow only to low-income residential and small business customers or do larger consumers also need assistance as they adjust to the new situation? Should the goal of the rebate application be to provide proportional assistance to all identified customers (such as by a percentage reduction in their total bills)? Or should a fixed monthly credit (say $\$ 10$ per month) be applied to all identified customers so that they continue to face the more efficient price for marginal use? Or should it go exclusively to investment in efforts to reduce consumption or load shift?

\section{Implications for Consumers}

A cap and trade program would necessarily have effects on consumers. The effects of allowance purchases in the auctions and subsequent allowance trading will likely increase the revenue requirement, at least for customers in regions that are highly dependent on carbonintensive electricity generation, but this will be offset to some extent by free allowances and the opportunity to sell excess allowances. The cost of new investment in lower carbonintensive generation, smart technology and new DSM programs will tend to increase revenue requirements in the short-term, but again there may be offsetting savings in operation expenses and government subsidies for some of these investments. The net effects on revenue requirements cannot be estimated until there is more information on the likely nature of the legislation and on the regulatory rules for treatment of utility gains from transactions.

Utility costs will certainly change at the margin, particularly energy costs, as the examples discussed above suggest. These changes will drive changes in the structure of rates.

Cap and trade will make dynamic pricing and load control programs more important than ever. Smart metering will provide new opportunities to put these new offerings in place, and assist consumers in responding.

Finally, consumers may face somewhat more volatile prices, both because of dynamic pricing and because of the inclusion of varying allowance costs/revenues in their rates.

\section{Next Steps}

Careful analysis of the details of a cap and trade program will be required to develop estimates of allowance costs and least-cost strategies for dealing with the new cost element. Regulators and utilities will probably need to work together to determine the strategies and mechanism for financing them. The effects of cap and trade on total revenue requirement and cost structures will require new rate studies that will probably require changes in existing rates as well as introduction of new rates and programs that take advantage of smart metering and associated communication and control capabilities. An integral part of the rate work will be to address the policy issues regarding any auction revenue rebates. Clearly, decision-makers will need comprehensive studies; follow-on workshops should provide opportunities for the stakeholders to work together to maximize achievement of the somewhat competing objectives. 


\section{Conclusions}

The electric generation industry is evolving with changes in the pricing and availability of fuels, changes in generating technology, changes in environmental regulations and changes in the structure of the market in which the generators operate. None of these changes occurs in a vacuum, and the complex interrelationships of these changes will affect the cost and sources of electricity. The economic viability of technology designed to change the time of day in which we use electricity depends not only on current market conditions, but on the market conditions of the future, which in turn rely on energy policy.

Using a dispatch model for electric generation, we have shown that the application of energy policy designed to reduce the overall emissions of carbon dioxide from the electric generation sector can have a marked effect on the characteristics of the marginal costs of electricity production. We have shown that the nature of the relationship between the higher cost hours and the lower cost hours can change not only through time, but also in response to the price of emitting carbon dioxide. We have also shown that these changes can include, under certain conditions, the reduction of the economic value of technologies designed to shift the consumption of electricity from one time period to another. The detailed study of the interrelationships of all of these policy and economic variables is critical to ensure the optimization of energy policy.

\section{References}

Florida Regional Coordinating Council (2009), Regional Load and Resource Plan

Kury, Theodore J, and Julie Harrington (2010), The Marginal Effects of the Price for Carbon Dioxide: Quantifying the Effects on the Market for Electric Generation in Florida, The Electricity Journal 23:4

U.S. Energy Information Administration (2010), Annual Energy Outlook 


\section{Notes}

* Hethie Parmesano is a Special Consultant with NERA Economic Consulting in Los Angeles. She can be reached at Hethie.Parmesano@ nera.com. Theodore J. Kury is Director of Energy Studies, Public Utility Research Center, University of Florida. He can be reached at Ted. Kury@warrington.ufl.edu. The authors are grateful for comments and suggestions by colleagues at NERA and PURC, including Mike King, Dan Radov, Sandy Berg and Lynne Holt, but accept responsibility for the opinions and any errors contained in this article.

1 The actual emissions might be lower if owners of allowances (for example environmental groups who have purchased some) choose not to use them.

2 While this may be necessary politically, it will likely be counterproductive to the goal of providing price signals that include the cost of the externality.

3 Plus marginal energy losses incurred to move that electricity to the customer's meter, and possibly some marginal cash working capital.
4 Predominantly hydro-electric systems may have a different basis for marginal energy cost because of the storability of water.

5 However, if free allowances are distributed on the basis of past or current energy output or emissions in a fixed period, this will affect the generator's total costs, but not the marginal value of capacity.

6 One argument against doing so is that the prices of complements to and substitutes for electricity do not include the cost of externalities.

7 This is the standard rate structure of real-time pricing programs.

8 Efficiency will also depend on the cost of the policy, and who pays that cost.

9 Approximately $10 \%$ of a typical month. 


\begin{abstract}
About NERA
NERA Economic Consulting (www.nera.com) is a global firm of experts dedicated to applying economic, finance, and quantitative principles to complex business and legal challenges. For half a century, NERA's economists have been creating strategies, studies, reports, expert testimony, and policy recommendations for government authorities and the world's leading law firms and corporations. We bring academic rigor, objectivity, and real world industry experience to bear on issues arising from competition, regulation, public policy, strategy, finance, and litigation.

NERA's clients value our ability to apply and communicate state-of-the-art approaches clearly and convincingly, our commitment to deliver unbiased findings, and our reputation for quality and independence. Our clients rely on the integrity and skills of our unparalleled team of economists and other experts backed by the resources and reliability of one of the world's largest economic consultancies. With its main office in New York City, NERA serves clients from more than 25 offices across North America, Europe, and Asia Pacific.
\end{abstract}

\title{
Contacts
}

For further information and questions, please contact the author:

\author{
Hethie Parmesano \\ Special Consultant \\ $+12133463010$ \\ hethie.parmesano@nera.com \\ Theodore J. Kury \\ Director of Energy Studies \\ University of Florida \\ +1 3523927842 \\ ted.kury@warrington.ufl.edu
}

